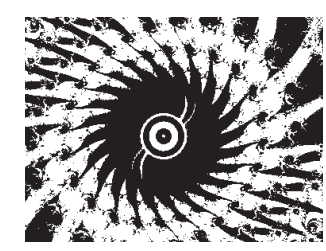

doi:10.5559/di.21.4.04

\title{
ŽENE I RODNE ULOGE U POSTSUPKULTURNOJ TEORIJI: PRIMJER RAVE KULTURE
}

Rašeljka KRNIĆ

Institut društvenih znanosti Ivo Pilar, Zagreb

UDK: 305-055.2:316.723"199"

Pregledni rad

Primljeno: 21. 5. 2012.

$U$ sedamdesetima $i$ do sredine osamdesetih godina $u$ sociološkom razmatranju povezanosti mladih, stila i glazbenog ukusa dominirao je koncept supkulturne teorije birminghamske škole, međutim već na početku osamdesetih neki su autori počeli propitkivati neke od osnovnih postarki dotadašnjih shvaćanja supkultura. Premda će se termin "postsupkulturno" pojaviti već kod Chambersa 1987. godine, u supkulturni diskurs uvest će ga, sredinom devedesetih, Polhemus (1996.) i Muggleton (1997.). "Postsupkulturne teoriije" zajednički je naziv za cijeli spektar koncepata i teorija s početka devedesetih, koje se i dalje bave sličnim fenomenima okuplianja mladih, ali koje više ne ustraju na zaključcima i pojmovnom aparatu supkulturnoga koncepta. Uz brojna područja kritike koja se odnose na problem klasne analize, pitanje otpora, neuvažavanje lokalnoga konteksta, ulogu medija itd., jedno od najznačajnijih odnosi se na zanemarivanje uloge žena u supkulturnim prostorima te jednodimenzionalno shvaćanje rodnih uloga i prirode seksualnosti. Postsupkulturne studije donose znatno više analiza koje ulogu žene u supkulturnim praksama i kulturnoj produkciji smještaju u središte svojeg interesa te otvaraju pitanja ženskog iskustva i ženske perspektive supkulturnog iskustva, a istraživanja raznih scena elektroničke glazbe upozorila su na rave kulturu kao distinktivni "supkulturni" prostor unutar kojeg dolazi do redefiniranja tradicionalnih rodnih uloga te značenja seksualnosti kroz promijenjene komunikacijske i interakcijske prakse.

Ključne riječi: birminghamska škola, postsupkulturna teorija, rodne uloge, rave kultura 
Od sredine prošloga stoljeća do danas pojam "supkultura" prolazi dug razvojni put, tijekom kojeg će unutar mnogih teorijskih okvira poprimati različite interpretacije i značenja. Temelje izučavanja supkultura nalazimo unutar tzv. "čikaške škole", koja se bavi istraživanjem društvenih grupa u urbanom kontekstu, a sam pojam "supkultura" počinje se rabiti 1950-ih godina u kontekstu analize delinkventnih obrazaca ponašanja. Koncept supkulture, proizašao iz "birminghamske škole" (koja se smatra najutjecajnijom teorijskom paradigmom koja se bavi ovom temom) na početku sedamdesetih, nastao je kao odgovor na pojavu novih životnih stilova i mladenačkih pokreta u šezdesetima i ranim sedamdesetim godinama. Iako je tijekom sedamdesetih i do sredine osamdesetih godina u sociološkom razmatranju povezanosti mladih, stila i glazbenog ukusa dominirao koncept supkulturne teorije, već na početku osamdesetih neki su autori, koji su i sami pripadali ili čak utemeljili "školu", počeli propitkivati neke od osnovnih postavki dotadašnjih shvaćanja supkultura. Kritike su donijele cijeli spektar primjedbi, između ostaloga kritiku jednodimenzionalnoga pogleda na otpor, nepriznavanje ukorijenjenosti supkulture u svakodnevni život, tretiranje supkultura kao homogenih društvenih grupa, prenaglašen fokus na "spektakularne" supkulture itd.

Od druge polovice osamdesetih sve više autora, istražujući raznovrsne životne stilove i mreže odnosa u kulturi mladih, odbacuje djelomično ili čak potpuno postavke proizašle iz birminghamske škole. Premda će se termin "postsupkulturno" pojaviti već kod Chambersa 1987. godine, u supkulturni diskurs uvest će ga, sredinom devedesetih, Polhemus (1996.) i Muggleton (1997.). "Postsupkulturne teorije" zajednički je naziv za cijeli spektar koncepata i teorija s početka devedesetih, koje se i dalje bave sličnim fenomenima okupljanja mladih, ali koje više ne ustraju na zaključcima i pojmovnom aparatu supkulturnoga koncepta. Postsupkulturno zapravo je najčešće postbirminghamsko, jer nove orijentacije grade teorije referirajući se uglavnom kritički na istraživanja iz sedamdesetih.

Iz perspektive većine teorija $u$ zadnjih dvadesetak godina, pristup birminghamske škole po mnogo čemu je problematičan. Zbog raspada supkulturnih podjela i sve veće stilske fluidnosti i fleksibilnosti, strukturno utemeljeni koncept supkulture, barem $\mathrm{u}$ onom striktnom smislu birminghamskoga perioda, za mnoge autore postaje suvišan, pa se sam pojam modificira ili potpuno odbacuje, dok se uvode neki novi pojmovi i koncepti koji bi trebali preciznije i razgovjetnije objasniti nove fenomene i oblike okupljanja mladih. Unutar novonastaloga diskursa ističe se kako kompleksna i promjenjiva priroda suvremenih mladenačkih kulturnih praksi, formi i 
DRUŠ. ISTRAŽ. ZAGREB GOD. 21 (2012),

BR. 4 (118),

STR. $885-900$

KRNIĆ, R.: ŽENE I... stilova ne može više biti objašnjena teorijskim okvirom unutar kojeg se supkulture analiziraju konceptom linearnoga vremena, gdje jedna, jasno definirana supkulturna, forma zamjenjuje drugu, a klasa se smatra jedinim determinirajućim faktorom, zanemarujući ostale strukturne odrednice kao što su spol, dob, etnička pripadnost itd. Uz brojna područja kritike koja se odnose na klasnu analizu, pitanje otpora, neprihvaćanje lokalnoga konteksta, ulogu medija itd., jedno od najvažnijih područja kritike supkulturnoga koncepta, ne samo u postsupkulturnom razdoblju nego i prije, tijekom dominacije birminghamske škole, odnosi se na zanemarivanje uloge žena u supkulturnim prostorima te jednodimenzionalno shvaćanje rodnih uloga i prirode seksualnosti. Angela McRobbie već je sedamdesetih godina upozoravala na prevlast istraživanja fokusiranih na supkulture koje čine manje-više isključivo muškarci. Međutim, iako su supkulture sedamdesetih uglavnom bile muški fenomen, i S. Cohen u svojoj studiji modsa i rockera "Folk Devils and Moral Panics" pokazuje kako su "u mnogo čemu modsi bili više ženski nego muški fenomen" (Cohen, 1987., 186). Prostor obitelji i obiteljskih odnosa bio je potpuno zanemaren unutar birminghamskoga teorijskog okvira, pa je $i$ to jedan od razloga izostanka djevojaka iz supkulturne analize. Postsupkulturne studije donose znatno više analiza koje ulogu žene u supkulturnim praksama i kulturnoj produkciji smještaju u središte svojeg interesa te otvaraju pitanja ženskog iskustva i ženske perspektive supkulturnog iskustva. Prva postbirminghamska istraživanja, na početku devedesetih godina, koja se posebno bave analizom uloge žena u supkulturnim praksama, odnose se na fenomen rave kulture, koji je, posebno u svojoj ranoj fazi, odražavao sasvim nove oblike socijalizacije, koji su upozoravali na promjene u odnosima među spolovima.

U prvom dijelu ovoga rada bit će govora o ranoj kritici birminghamske škole, tj. izostanku istraživanja koja se tiču ženskoga supkulturnog iskustva. Upozorit će se i na širi društveni kontekst koji je utjecao na otvaranje novoga istraživačkog prostora devedesetih, unutar kojeg će se kroz postsupkulturne teorije žene prepoznati kao važan i zanimljiv akter supkulturnih svjetova. U drugom dijelu rada analizira se primjer scene elektroničke glazbe kao distinktivnoga supkulturnog prostora, unutar kojeg dolazi do redefiniranja tradicionalnih rodnih uloga te značenja seksualnosti kroz promijenjene komunikacijske i interakcijske prakse.

\section{(NE)VIDLJIVA ŽENA}

Angela McRobbie, koja je i sama pripadala birminghamskoj školi, napisala je 1975. godine, u koautorstvu s Jenny Garber, vrlo kritičan tekst o dotadašnjim istraživanjima CCCS-a. Radi se o klasičnom tekstu za područje supkulturne analize pod 
DRUŠ. ISTRAŽ. ZAGREB GOD. 21 (2012) BR. 4 (118)

STR. $885-900$

KRNIĆ, R.: ŽENE I... nazivom "Girls and Subculture", u kojem se prvi put upozorava kako supkulturna istraživanja gotovo potpuno ignoriraju ulogu djevojaka u mladenačkim kulturnim grupama. Djevojke su nevidljive u svim klasičnim supkulturnim etnografskim studijama, povijestima popularne kulture i novinarskim tekstovima na tom području, a onda kada ih se i spominje, to je najčešće u kontekstima koji nekritički osnažuju stereotipno shvaćanje žene kao manje-više isključivo seksualni objekt. McRobbie i Garber pitaju se zar djevojke zaista nisu prisutne u supkulturnom životu ili se zapravo radi o načinu na koji se provode istraživanja koja ih čine nevidljivima.

"Je li to jednostavno tipičan tretman djevojaka koji odražava prirodni odnos muškog istraživača i njegovih muških ispitanika? Ili je pak istraživaču koji, ipak, proučava bajkere, teško ne shvatiti ozbiljno način na koji ti momci promatraju djevojke?" (McRobbie i Garber, 1997., 113).

Skoro 25 godina kasnije, baveći se sličnim problemom, Leblanc (2001.) nakon iscrpne revizije literature o supkulturama zaključuje kako istraživači vrlo rijetko dopuštaju da se u razmatranjima o supkulturnim aktivnostima čuje i ženski glas. Nadalje, autorica upozorava kako nije dovoljno samo konstatirati prisutnost djevojaka u supkulturnim svjetovima, nego treba istražiti i analizirati odnose među spolovima unutar tih "prostora", norme koje iz tih odnosa proizlaze i način na koji se mlade djevojke prema njima odnose.

"Supkulturna participacija djevojaka (obično) je opisivana na prvenstveno seksualiziran način, a njihov vid devijantnosti uziman je, zdravo za gotovo, kao seksualan i povezan s nekim muškim članom. A opet, teško je zamisliti zašto bi djevojke prilazile, i ostajale, ako ih se prihvaća samo kao muške igračke. [...] Kad se istraživači izričito fokusiraju na prikupljanje svjedočenja iz prve ruke o položaju djevojaka i žena u supkulturama u kojima dominiraju muškarci, otkrivaju da su njihovi motivi mnogo kompleksniji i važniji nego što se ranije mislilo" (Leblanc, 2001., 68).

McRobbie je u svojim ranim, ali i kasnijim, radovima vrlo kritična prema istraživanjima svojih, uglavnom muških, kolega, upozoravajući na mnoge probleme u pristupu. Istraživanjima su dominirali muškarci i kao istraživači i kao ispitanici, što bi mogao biti uzrok prikazivanja djevojaka u podređenom položaju u odnosu na muške vršnjake i nedostatka potrebe da se istraže alternativni kulturni prostori u kojima djevojke itekako mogu imati glavnu ulogu. Iz njezina rada proizlazi kako nije riječ o pitanju vidljivosti ili nevidljivosti djevojaka u muškim supkulturama, nego kako je važno analizirati komplementarne načine interakcije među mladim djevojkama 
DRUŠ. ISTRAŽ. ZAGREB GOD. 21 (2012),

BR. 4 (118),

STR. $885-900$

KRNIĆ, R.: ŽENE I... koje stvaraju svoje distinktivne supkulturne svjetove, koji funkcioniraju na sebi svojstven način. Kao primjer navodi se "teenybopper" kultura, nastala oko djevojačke zaluđenosti brojnim muškim pop-zvijezdama toga vremena. Iako je autorica svjesna kako je ova vrsta supkulture, a i "kultura djevojačke spavaće sobe", bitno različita od muških supkultura radničke klase, kojima se pripisuju elementi kreativnosti i otpora, ono na što želi upozoriti jest postojanje i ženskih supkultura, koje su također određene ekskluzivnošću i specifičnim kodovima ponašanja. Ono što proizlazi iz takvih analiza upućuje na to da djevojke konstruiraju drugačije "prostore" dokolice od svojih muških vršnjaka i unutar kojih imaju mogućnost drugačije vrste otpora. Centralni prostori unutar kojih su organizirane muške supkulture 60-ih i 70-ih uglavnom se odnose na javni prostor, ulicu i kvart, dok su mlade djevojke uglavnom zaokupljene aktivnostima poput slušanja i skupljanja ploča, magazina i postera svojih omiljenih pop-zvijezda, što se odvija unutar privatne sfere doma. ${ }^{1} \mathrm{U}$ svojim kasnijim radovima McRobbie će ponuditi analize mnogo produktivnijih koncepata ženskosti koji se bave pitanjem ukusa, užitka, supkulturnoga poduzetništva i kreativnosti, o čemu će više riječi biti kasnije u tekstu. Iako je McRobbie već sredinom sedamdesetih kritički propitkivala rad "škole" kojoj je i sama pripadala, ipak nije dovodila u pitanje same temelje supkulturnoga koncepta, nego je svoja razmatranja uloge djevojaka i dimenzije spola i roda ostavila unutar supkulturne paradigme koja generalni društveni kontekst $\mathrm{u}$ kojem nastaju supkulture analizira pojmovima klase, škole, rada, dokolice, obitelji, naglašavajući važnost strukturnih elemenata.

Postsupkulturno razdoblje na početku devedesetih godina donosi otvaranje potpuno novoga diskursa (sup)kulturne analize, unutar kojeg se na razne načine i na raznim primjerima razmatraju problemi odnosa među spolovima, prezentirajući često ženu kao središnji subjekt supkulturnih praksi i kulturne produkcije. Pa tako, na primjer, Doreen Piano (2003.) $\mathrm{u}$ tekstu "Resisting Subjects: DiY Feminism and the Politics of Style in Subcultural Production" analizira utjecaj "trećeg vala" feminizma na mladenačke kulture u SAD-u potkraj osamdesetih, koristeći se primjerom riot grrrl pokreta koji su činile "razočarane, ogorčene, gnjevne, frustrirane i isključene" žene okupljene u punk bendovima da bi pokazale kako predstavljaju nešto više od seksualnog objekta i pasivna promatrača (Piano, 2003., 253). U tom razdoblju nastao je niz ženskih punk bendova koji su poharali američke lokalne punk scene, sastavljene uglavnom od bijelih muškaraca, doslovno vrišteći o svojoj isključenosti i rušeći tako "mit o punkerskom egalitarizmu" (Nguyen, 2001., 179). Žene su bile dijelom punk pokreta od samoga početka, mnoge privučene retorikom o ravno- 
DRUŠ. ISTRAŽ. ZAGREB GOD. 21 (2012) BR. 4 (118),

STR. $885-900$

KRNIĆ, R.: ŽENE I... pravnosti i suzbijanju tradicionalnih spolnih uloga, međutim njihove pozicije na sceni gotovo nikad nisu bile središnje, a kada bi se za takvu pokušale izboriti, često bi bile ismijavane ili podvrgnute fizičkom i verbalnom nasilju. Rane punk feministice otvorile su put za kreiranje alternativnih, osnaženih uloga djevojaka unutar supkultura, koje su potkraj osamdesetih, na punk sceni, kroz kreativne supkulturne prakse poput sviranja $u$ bendovima i izdavanja fanzina mijenjale definiciju ženskosti, pomičući se iz pozicije pasivnoga promatrača prema poziciji produktivnoga subjekta (Piano, 2003.). Do vrlo sličnih zaključaka dolazi i Hellen Reddington (2003.), ističući kako - za razliku od Stanleya Cohena, koji smatra da se povijesti britanskih poslijeratnih supkultura više nema što dodati - $\mathrm{u}$ akademskim i novinskim tekstovima nedostaje cijela jedna dimenzija povijesti punka. Dimenzija ženske uloge. U tekstu "Lady" Punks in Bands: A Subculturette? analizira niz događaja koji su uveli žene u do tada pretežno muški svijet rock i punk bendova te način na koji je njihova prisutnost taj svijet uzdrmala i promijenila.

Sredinom sedamdesetih Angela McRobbie uložila je mnogo truda u problematiziranje marginalizacije djevojaka u supkulturnom životu i manjak konstruktivnog interesa da se o njihovim ulogama više sazna, ${ }^{2}$ dok je rad Dicka Hebdigea bio isključivo usmjeren na krajnje supkulturne produkte i promjene značenja proizašle iz načina na koji su se rabili, a kulturna produkcija, tj. infrastrukturna pozadina supkulture, ostala je nevidljiva za analizu. Kao što je već rečeno, McRobbie (1994.) tvrdi kako se supkulturna teorija odupirala analizi procesa proizvodnje, marketinga i potrošnje, jer je to za veći$\mathrm{nu}$ autora bio onaj moment $\mathrm{u}$ kojem opozicijska snaga biva inkorporirana ili vraćena $u$ društvo kroz procese komodifikacije. Međutim, vrlo je brzo postalo jasno da je romantična ideja o autentičnosti idealizirajuća i neodrživa. Supkultura nije stajala uzvišeno naspram "kontaminiranog vanjskog svijeta" koji vreba da je upakira u komercijalno isplativ proizvod, nego su ta dva svijeta bila neraskidivo povezana i potrebna jedan drugom da bi rasli i razvijali se (McRobbie, 1994., 161). Aktivnosti poput produkcije magazina od strane fanova, kreiranje, kupovanje, prodavanje i nošenje određene odjeće, produkcija glazbe itd. više su od same prezentacije supkulture. One su, iako dijelom komercijalne, vrlo vjerojatno središnje aktivnosti koje održavaju supkulturu.

"Kupovina, prodaja i produkcija ne odvijaju se u vakuumu. Integralno su povezane s mnogo dužim lancima značenja i vrijednosnim sustavima. Rabljena odjeća i etika recikliranja koja ide uz nju, na primjer, ne stvaraju samo "retro" imidže na ulicama već pružaju i kontrapunkt preskupoj ekskluzivnoj modi. Prodaja takve odjeće zahtijeva organizacijske sposobnosti i maštu" (McRobbie, 1994., 162). 
DRUŠ. ISTRAŽ. ZAGREB GOD. 21 (2012),

BR. 4 (118),

STR. $885-900$

KRNIĆ, R.: ŽENE I...
Marginaliziranje značenja ovoga tipa aktivnosti, vezanih za modu, učinilo je i uključenost djevojaka u supkulturni život nevidljivim, jer upravo su kreativne i poduzetničke prakse vezane za odjeću područje na kojem su djevojke aktivnije. Taj tip praksi ne samo da je od ključne važnosti za mladenačku kulturu nego je, ističe autorica, presudan za integraciju mode u supkulturni stil. Istraživanja Angele McRobbie pokazala su kako naglasak na kulturnu produkciju razotkriva mnogo višu razinu uključenosti djevojaka u supkulture nego što se to moglo iščitati iz teorija sedamdesetih i osamdesetih.

Postsupkulturno razdoblje donijelo je odmak od postavki birminghamske škole, otvarajući prostor za kulturne analize koje više ne tretiraju klasu kao glavni pojam, nego se okreću istraživanju značenja koja uključuju i pitanja rodnih identiteta, seksualnosti, rase, etničke pripadnosti itd. Jedan od tih problema tiče se i "mijenjajućih modusa ženskosti" (McRobbie, 1994., 157). Društvene promjene u zadnjih dvadesetak godina donijele su potrebu za revizijom dotadašnjih teorija i konstrukcijom novih paradigmi, unutar kojih će se moći analizirati sve veća fluidnost značenja koja se vezuju uz pojam ženskosti i način na koji se ta značenja upisuju u društvenu realnost. Bez obzira na način na koji se žene prikazuju u medijima, posebno tabloidima, feminističke ideje imale su dramatičan utjecaj na gotovo sve razine društvenoga života u Britaniji. Pitanja spolne (ne)ravnopravnosti, i u sferi doma i u javnoj domeni, postala su važnim dijelom političkoga diskursa, a javne institucije, osobito u sektoru obrazovanja, sve više prepoznaju ženu kao važan subjekt kulturnoga i ekonomskoga života. Te su promjene uvelike potkopale tradicionalno shvaćanje ženskog identiteta, koji je dugo bio vezan uz ulogu žene u kući, kao majke i supruge koja se rijetko u svijetu rada ostvaruje na istoj razini kao i muškarci. Feminističke ideje prodrle su u gotovo sve sfere kulture, a ne samo one koje su tradicionalno bile povezane sa ženskosti (McRobbie, 1994.), što se također odnosi na vidljive promjene u sferi ženskoga supkulturnog iskustva. Primjer rave kulture $\mathrm{u}$ tom kontekstu u ovom je radu odabran zato što su postsupkulturna istraživanja i analize kulture nastale oko elektroničke glazbe, na početku devedesetih, razotkrile sasvim nove (sup)kulturne obrasce i prakse koje su odražavale važne promjene u odnosima među spolovima i načinu na koji se formiraju rodni identiteti.

\section{ŽENE, RODNI ODNOSI I SEKSUALNOST U RAVE KULTURI}

Jedan je aspekt rave kulture posebno zanimljiv za analizu mnogim postsupkulturnim teoretičarima, a tiče se prirode seksualnosti i odnosa među spolovima na suvremenom plesnom podiju elektroničke glazbe. Pojavom rave kulture potkraj osamdesetih godina prvi se put formirala supkultura koja je u- 
DRUŠ. ISTRAŽ. ZAGREB GOD. 21 (2012) BR. $4(118)$

STR. $885-900$

KRNIĆ, R.: ŽENE I... kinula tradicionalne rodne uloge, utemeljene na seksualnoj tenziji, i donijela kulturne prakse koje su bitno odskakale od onih s kojima su se teoretičari do tada susretali istražujući supkulture mladih. Do osamdesetih su plesne dvorane bile prostori seksualnoga naboja, a djevojke su bile seksualni objekt i glavni razlog zbog kojeg su muškarci dolazili na takva mjesta. Plesanje je bilo oblik erotske ekspresije i seksualnog izlaganja, gdje bi muškarci često promatrali žene kako plešu prilazeći im onda kada ih žele zavesti (Mungham, 1976.). Na ples se vrlo često gledalo kao na primarno žensku aktivnost, kao nešto što je stajalo u žarištu njihova supkulturnog iskustva (Gilbert i Pearson, 1999.; McRobbie, 1994.), a u drugom dijelu 20. stoljeća plesna glazba dijelom se poistovjećivala sa gay kulturom (Gilbert i Pearson, 1999.). Gilbert i Pearson (1999.) također upozoravaju kako su ples i ženskost jedini pojmovi koje falocentrizam marginalizira, pa su zato ples i ženska perspektiva dugo bili zanemareni i sasvim izvan interesa znanstvene analize. Međutim, neočekivani socijalni odnosi i (sup)kulturne prakse rave pokreta otkrili su novi prostor drugačije artikulacije ženskosti i novoga shvaćanja i funkcije plesa bez obzira na spol. Angela McRobbie zapaža:

"Djevojke su se u supkulturama uvijek nalazile u plesu. To im je bilo jedino pravo. A sada, u rejvu to postaje pokretačka sila cijele supkulture. To djevojkama daje novo samopouzdanje i važnost" (McRobbie, 1994., 169).

Odjeća na rave partyjima, posebno prvih godina kada je pokret bio u začetku, bila je vrlo karakteristična, s tim da su djevojke nerijetko bile vrlo oskudno odjevene, u jako kratke, takozvane "vruće", hlačice i topiće, što na prvi pogled ostavlja dojam izrazito seksualizirane atmosfere. Međutim do tada uobičajena konstelacija na plesnom podiju raznih supkultura, gdje djevojke plešu, a muškarci uglavnom gledaju, ovdje se ukida, jer je odnos lišen seksualne konotacije u tradicionalnom smislu. Želju za seksualnim osvajanjem i potrebu za zavođenjem zamijenio je čisti užitak plesanja. Rave kultura prvi put omogućuje ženi da izmakne muškom pogledu i tako bude oslobođena statusa seksualnog objekta.

"Od jivea do break dancea tijelo je tradicionalno strukturirao (muški) pogled koji je plesu davao značenje ekshibicije. Drukčiji smisao plesa u Acid Houseu sugerira Jenny Rampling iz Shoom Cluba: ljudi dolaze jer se mogu potpuno opustiti i razvaliti, a da ih nitko ne gleda" (Melechi, 1993., 33).

Odjevni stil djevojaka, posebno na ranim rejvovima $\mathrm{s}$ početka devedesetih, često je podrazumijevao neobičnu, na neki način i kontradiktornu, kombinaciju izrazito erotične o- 
DRUŠ. ISTRAŽ. ZAGREB GOD. 21 (2012), BR. 4 (118),

STR. $885-900$

KRNIĆ, R.: ŽENE I... djeće i predmeta koje povezujemo s djecom, kao što su dude, zviždaljke, lizalice, plišane igračke itd. Iako odjeća naglašava seksualnost, ona se istodobno negira dječjim simbolima i djetinjastim ponašanjem. McRobbie (1994.) objašnjava kako se radi o kulturi droge koja maskira svoju nevinost u dječji jezik, a supkulturni stil služi kao metafora seksualne zaštite. Iako autorica afirmativno piše o rejvu i plesnom podiju kao potencijalno autonomnom kulturnom prostoru za mlade žene, ona ipak primjećuje kako su djevojke osjetno manje uključene u kulturnu produkciju, poput izradbe flajera, plakata, organizacije partyja, dj-inga, produkcije glazbe itd. nego što su to muškarci. Organizaciju preuzimaju poslovni ljudi, koji u rejvu vide mogućnost za dobru zaradu, tako da je komercijalizacijom rave izašao iz sfere isključivo manjih organizacijskih pothvata vezanih uz supkulturu te postao unosan posao. Organizatori su uglavnom stariji muškarci, s iskustvom u klupskoj promociji, dok djevojke uglavnom rade sporedne poslove, dijele flajere i slično. U tom kontekstu riječ je o kulturnom miljeu koji reproducira norme koje su na snazi u većini drugih radnih okruženja (McRobbie, 1994.). I Maria Pini (Pini, 1997.a, b) upozorava kako su žene uglavnom marginalizirane kad je riječ o glavnim supkulturnim aktivnostima - od glazbene produkcije i organizacije pa do dilanja droge. Iako mnoge žene sudjeluju u supkulturnim praksama koje čine scenu, konstruirajući svoj identitet aktivnostima vezanima uz rave, njihova je uloga često zanemarena, jer se naglasak uvijek stavlja na one vidljive, tradicionalno više vrednovane, aspekte uključenosti, koji muškarca stavljaju u središte pozornosti, dok žena ostaje nevidljiva.

U pokušaju da ispravi ili bar donekle ublaži takvu nepravdu, Maria Pini provela je istraživanje na ranoj britanskoj rave sceni, koje smješta ženu u položaj središnjega, aktivnog subjekta kroz analizu uključenosti na nekim drugim razinama, a ne isključivo onima na kojima su muškarci brojčano dominantni. Izostajanje djevojaka iz toga tipa praksi ne smije dovesti do pogrešnoga zaključka kako je djevojkama prisutnost na sceni i identitet koji se uz nju veže manje važna nego muškarcima.

\footnotetext{
"Za mnoge žene rave predstavlja ukidanje tradicionalne kulturne asocijacije između rasplesane, drogirane, 'uređene' žene i seksualnog poziva, i kao takav otvara novi prostor za istraživanje novih oblika identiteta i zadovoljstva" (Pini, 1997.b, 154).
}

Povijest zapadne civilizacije ujedno je i povijest represije nad tijelom, posebno ženskim tijelom, koje je specifičnim praksama, ideologijama i diskursom marginalizirano, kontrolirano i definirano prema muškim kriterijima, a ondje gdje po- 
DRUŠ. ISTRAŽ. ZAGREB GOD. 21 (2012) BR. $4(118)$

STR. $885-900$

KRNIĆ, R.: ŽENE I... stoji represija, uvijek postoji i mogućnost "pobune" protiv etabliranih normi i otvaranja prostora, gdje identitet i dominantni diskurs postaju predmet pregovaranja. Analiza M. Pini pokazuje kako se rave kultura u određenim aspektima može promatrati kao izazov tradicionalno centralnim heteroseksualnim, muškim normama i u žarište istraživanja postavlja žensko iskustvo, osobna značenja koja pridaju djelovanju na sceni, te otkriva kako se proizvode i generiraju specifična značenja i iskustva koja iz toga djelovanja proizlaze. Osnovna preokupacija odnosi se na pitanje zašto žene govore o rejvu kao o seksualno progresivnoj kulturi i prostoru koji omogućuje nove oblike subjektiviteta.

Mladenačke kulture koje su prethodile rejvu temeljile su se na izražavanju "političkog", na ljutnji, na simboličkom otporu, na isticanju stila. Međutim, kako misli M. Pini, potreba za dostizanjem "ekstaze", fizičkoga i mentalnoga zadovoljstva, postaje glavni aspekt te nove kulture nastale oko elektroničke glazbe. Autorica identificira određene aspekte rejva kao "tekst uzbuđenja" (Pini, 1997.b, 159). A uzbuđenje i zadovoljstvo proizlaze dijelom iz konzumiranja plesnih droga i transičnoga plesa, koji vode u poseban osjećaj ekstaze potpunim predavanjem glazbi. Ono što je ovdje važno naglasiti jest činjenica da se žene na ranoj rave sceni, za razliku od scena koje su joj prethodile, na isti način kao i muškarci prepuštaju uzbuđenju i ekstatičnim stanjima. Njima je rave prvi put omogućio prostor progresivnih seksualnih politika i redefiniranih rodnih uloga.

"Za mnoge je žene rave i privlačan ponajviše zbog odsutnosti heteroseksualnog 'skupljanja' ('upucavanja', 'zašprehavanja' itd.). Većina njih spominje opću odsutnost agresivnosti i mnoge kontrastiraju klubove u kojima se uzima ecstasy i mjesta gdje se mnogo konzumira alkohol. Umnogome, privlačnost rejva povezana je s percipiranom odsutnosti određene vrste muškosti i odnosa na plesnom podiju koji se povezuju s tradicionalnim plesnim klubovima" (Pini, 1997.b, 160).

Jedno od bitnih određenja rane rave scene odnosi se na atmosferu, o kojoj su mnogi pisali kao oslobađajućoj u smislu ukidanja socijalnih granica i isključivanja bilo koje vrste. O tom aspektu Pini govori kao o "tekstu jednakosti" (Pini, 1997.b, 161). Erozija razlika među spolovima djelomično se odvija i zahvaljujući odjevnom stilu koji se nije pretjerano razlikovao u odnosu na spol. Ukidanje socijalnih granica često se pripisuje i empatičnom djelovanju ecstasyja, međutim autorica nalazi kako samo određeni broj rejvera uzima tu drogu, tako da se takav fenomen ne može objasniti isključivo djelovanju ec- 
DRUŠ. ISTRAŽ. ZAGREB GOD. 21 (2012),

BR. 4 (118),

STR. $885-900$

KRNIĆ, R.: ŽENE I... stasyja, jer je on samo jedan element u cjelini iskustva. Mnoge su ispitanice svjedočile o osjećaju "gubitka sebe" da bi se postalo dijelom nečeg "većeg, nečeg što nadilazi vlastiti ego i uobičajeno poimanje sebstva" (Pini, 1997.b, 161). Tim Jordan takvo iskustvo vidi kao postupni gubitak subjektivnoga doživljaja sebstva, spajajući se u "kolektivno tijelo" (Jordan, 1995., 125). Tradicionalna podjela na "ja" i "drugi" ovdje se ukida, što dovodi u pitanje liberalno humanističko stajalište o jedinstvenoj individui kao središtu svjesnosti (Geertz, 1979.). U analizama M. Pini (Pini, 1997.a; 1997.b) upravo je ukidanje jasne granice između sebe i drugih isplivalo kao jedan od centralnih aspekata iskustva kolektivnoga plesanja na rave partyjima. Rave treba promatrati kao kulturu "tijela", ali "tijela" koje više nije razdvojeno od uma i duha, nego postoji povezanost i ravnoteža koja ukida standardni tijelo/um dualizam. Zadovoljstvo i pripadanje proizlazi iz povezanosti s drugima, a individualna svijest, pa tako i seksualnost, padaju u drugi plan ili čak smetaju potpunom iskustvu prepuštanja.

\footnotetext{
"Mnogi na plesnoj sceni imali su osjećaj da se društvene zapreke ruše; kako često nisu imali iskustvo iz prijašnjih supkultura, to jedinstvo činilo im se izvanrednim i novim. Crni ili bijeli, muški ili ženski, gay ili hetero, bogati ili siromašni, plesni podij pružio je alternativu podijeljenom društvu" (Wright, 1998., 233).
}

Pogled na tijelo koje pleše više nije seksualno objektiziranje i separacija, nego signalizira sasvim novo shvaćanje tjelesnosti, oslobođene od spola, naglašavajući na taj način osjećaj jedinstva i uključenosti.

Istraživanje M. Pini donosi sasvim novu perspektivu na žensko supkulturno iskustvo, koje na ranoj britanskoj rave sceni odskače od uobičajenoga shvaćanja uloge djevojaka na drukčijim supkulturnim prostorima. Iskustvo lišeno seksualne dimenzije, koja ih je često stavljala u položaj objekta i unaprijed određivala kodove ponašanja, omogućilo je mladim djevojkama stvaranje prostora za formiranje novog i drukčijeg identiteta, koji, između ostalog, podrazumijeva i potrebu za afektivnim izražavanjem, potragu za osobnim zadovoljstvom i redefiniranjem intersubjektivnosti. Iz njezinih istraživanja proizlazi kako je rave, kao "alternativni" prostor, otvorio mogućnost za kreiranje novih oblika ženskosti, oslobođenih od tradicionalnih konotacija, gdje žena napokon pleše slobodno, a da se takav čin ne tumači kao seksualan. Bez obzira na relativnu odsutnost djevojaka iz organizacijskih poslova i glazbene produkcije, pojava rejva pretpostavlja važan pomak u rodnim odnosima i redefiniranju uloge žena u (sup)kulturnim prostorima. 
DRUŠ. ISTRAŽ. ZAGREB GOD. 21 (2012) BR. $4(118)$

STR. $885-900$

KRNIĆ, R.: ŽENE I...
Nešto drugačiji pogled na sličan problem donosi također etnografsko istraživanje Bena Malbona (1999.) na britanskoj sceni s kraja 1990-ih. Njegovi nalazi upućuju na to da je slika koju su McRobbie i Pini prikazale samo djelomična i da joj nedostaju drugačiji aspekti iskustva. Iako su neke od djevojaka iz njegova istraživanja potvrdile nalaze autorica o promijenjenim intersubjektivnostima i deseksualizaciji kroz potragu za ekstatičnim zadovoljstvom, dio ispitanica opisuje sasvim drukčija iskustva s plesnoga podija, gdje su seksualizirane prakse jednako važne, ako ne i važnije nego u drugim društvenim prostorima. Takvo je iskustvo također nazvano oslobađajućim, međutim s potpuno drukčijim predznakom nego ono opisano u studiji M. Pini. Malbon ga naziva "hiperseksualizacijom" (Malbon, 1999., 194).

Iako je seksualna interakcija tijekom večeri u klubu manje važna, autor naglašava kako klub ipak ostaje važno mjesto za traženje budućih seksualnih partnera. Za razliku od McRobbie, koja govori o deseksualizaciji plesnoga podija, autor nalazi kako neke žene doživljavaju partyje kao prostor za ekspresiju izrazito naglašene seksualnosti, ali poput M. Pini primjećuje kako tako izražena seksualnost često ima autoerotičan karakter i nije sredstvo za pronalaženje partnera. Ovakvi rezultati pokazuju kako se ne radi o potpunoj deseksualizaciji žene u rave kulturi, jer će neke od njih isticati svoju seksualnost, dok će je neke staviti u drugi plan, pa seksualnost ostaje važna, ali na neki drugi način. Slično zaključuje i Hemment:

"Plesna kultura uvela je amorfniju i difuzniju seksualnost koja je dala ženama i gayevima više prostora za aktivno izražavanje, a da nije nametala mnoštvu nikakav određeni stav ili orijentaciju. No ostao je stupanj muške dominacije, jer ta je neodređenost ostala nerefleksivna i tako nastavila postojati uz tradicionalne rodne odnose i seksualne nazore" (Hemment, 1998., 215).

Redefiniranje prirode seksualnosti i rodnih identiteta jamačno je scenu elektroničke glazbe učinilo distinktivnim kulturnim prostorom koji nije definiran (isključivo) tradicionalnim konotacijama "ženskosti" i "muškosti". U tom smislu možemo govoriti o interakcijskim praksama koje se mogu iščitati kao oblik otpora, pogotovo ako otpor shvatimo kao mikropolitike koje se temelje na nekonvencionalnim oblicima komunikacije i konstrukciji identiteta kroz otklon od uobičajenih normi. Međutim, treba naglasiti kako je značenje određenih praksi koje mogu biti analizirane kao "emancipacija" uvijek kontekstualno, pa potpuno iste manifestacije u različitim kontekstima mogu imati sasvim drukčiji predznak, i utoliko je 
kulturne prakse važno analizirati uzimajući u obzir specifičan kontekst $\mathrm{u}$ kojem se događaju, da se ne bi upalo u zamku teorijskog uopćavanja.

\section{ZAKLJUČNO}

Analize socijalne interakcije unutar suvremene klupske kulture upućuju na transformaciju kodova uobičajene fizičke i verbalne komunikacije između muškaraca i žena unutar rave kulture. Iako je scena elektroničke glazbe danas izrazito fragmentirana i stratificirana, pa teško možemo govoriti o transformaciji na općem planu jer svi dijelovi scene ne funkcioniraju na isti način, ipak se može zaključiti da je ovaj (sup)kulturni milje (ili neki njegovi dijelovi) stvorio autonoman prostor što ga karakterizira odbijanje uobičajenih normi ponašanja i pripisanih rodnih identiteta. Supkulturno iskustvo partyja prvi put podrazumijeva ples kao središnju praksu, a užitak plesanja kao osnovnu pokretačku snagu ovoga pokreta, koji je na potpuno isti način važan i muškarcima i ženama i gdje su tradicionalne podjele uloga ukinute (do pojave rave kulture plesanje je bila jedina supkulturna praksa koja se dovodila u vezu sa ženama i koju se držalo inferiornom u odnosu na "muške" prakse). Party za mnoge aktere znači oslobađajuće iskustvo izmicanja rodnim identitetima, $\mathrm{i}$ to ne samo u kontekstu tradicionalne represije nad ženskim tijelom nego i u smislu otvaranja prostora za redefiniranje uloge muškarca, koji biva oslobođen, barem trenutačno, od društvenoga pritiska da bude "muškarčina". Kroz zajednički ritual plesa i ostalih praksi, koje mogu dovesti do ekstatičnih stanja i oceanskog iskustva koje oslobađa tijelo, ponekad dolazi do trenutačne dekonstrukcije opozicije između "ženskosti" i "muškosti", i u tom smislu možemo govoriti o iskustvu koje stoji izvan diskursa što ga fiksira rodni identitet. Unutar tako konstruiranoga "prostora" žena ne samo da biva oslobođena od tradicionalne konotacije ženskosti nego je njezina uloga u (sup)kulturnim praksama koje konstituiraju ovu scenu u odnosu na mnoge prijašnje i suvremene (sup)kulture posredovane glazbom i stilom jednako važna i "vidljiva" kao i uloga muškarca. Iako je redefiniranje odnosa među spolovima u kontekstu rave kulture ženu napokon postavilo u ravnopravan ili, bolje rečeno, ravnopravniji položaj prema muškarcima, treba napomenuti kako se ta novonađena ravnopravnost $i$ "vidljivost" uglavnom odnose na onaj aspekt iskustva koji se ne tiče proizvodnje ključnih kulturnih artefakata i utjecaja na razvoj scene kroz organizacijske prakse. U tom smislu teško možemo govoriti o potpuno uravnoteženim odnosima moći unutar scene, pa se čini kako je taj ideal ipak još daleko. Međutim, bez obzira na to, redefiniranje rodnih uloga kroz drugačije interakcijske 
DRUŠ. ISTRAŽ. ZAGREB GOD. 21 (2012), BR. $4(118)$

STR. $885-900$

KRNIĆ, R.: ŽENE I... prakse možemo promatrati u kontekstu promijenjenih "seksualnih politika" unutar rave kulture, a koje predstavljaju otklon od uobičajenih normi i suspenziju dominantnih kodova ponašanja, pa u ovom aspektu možda leži i najsnažniji emancipacijski potencijal ovoga (sup)kulturnog pokreta.

\section{BILJEŠKE}

\section{LITERATURA} ber, iako vrijedan, na neki način problematičan upravo zbog primjera "teenybopper" kulture, koja teško da unosi "progresivne modele ženskosti u supkulturu" (Gelder, 1997., 86). Iako Gelder ovdje ima potpuno pravo, treba uzeti u obzir da se radi o ranom pokušaju da se otvori novi istraživački prostor u kojem će djevojke ubuduće biti uzete u obzir kao aktivni subjekti u izgradnji supkulturnih mikrosvjetova, ne samo onih koji se odnose na tradicionalno ženske aktivnosti nego i onih koji su se uobičajeno tretirali kao isključivo muški.

2 Međutim, tek će se kasnije ozbiljnije pozabaviti istraživanjem praksi i aktivnosti kojima su djevojke svakodnevno sudjelovale u održavanju pojedinih supkultura na životu.

Chambers, I. (1987). Maps for the metropolis: A possible guide to the present. Cultural Studies, 1(1), 1-21. doi:10.1080/09502388700490011

Cohen, S. (1987). Folk devils and the moral panics: The creation of the mods and rockers. Oxford: Basil Blackwell.

Geertz, C. (1979). From the native's point of view: On the nature of anthropological understanding. U P. Rabinow i W. M. Sullivan (Ur.), Interpretive social science (str. 225-241). Berkeley: University of California Press.

Gelder, K. (1997). Introduction to part two. U K. Gelder i S. Thornton (Ur.), Subcultures reader (str. 83-89). London: Routledge.

Gilbert, J. i Pearson, E. (1999). Discographies: Dance music, culture and the politics of sound. London and New York: Routledge.

Hemment, D. (1998). Dangerous dancing and disco riots: The northern warehouse parties. U G. McKay (Ur.), DIY culture: Party and protest in nineties Britain. London: Verso.

Jordan, T. (1995). Collective bodies: Raving and the politics of Gilles Deleuze and Felix Guattari. Body and Society, 1(1), 125-144. doi:10. 1177/1357034X95001001008

Leblanc, L. (2001). Pretty in Punk: Girls' gender resistance in a boys' subculture. New Brunswick: Rutger's University Press.

Malbon, B. (1999). Clubbing: Dancing, ecstasy and vitality. London \& New York: Routledge.

McRobbie, A. (1994). Postmodernism and popular culture. London: Routledge.

McRobbie, A. i Garber, J. (1997). Girls and subcultures. U K. Gelder i S. Thornton (Ur.), Subcultures reader (str. 112-120). London: Routledge. 
DRUŠ. ISTRAŽ. ZAGREB GOD. 21 (2012), BR. 4 (118),

STR. $885-900$

KRNIĆ, R.: ŽENE I...
Melechi, A. (1993). The ecstasy of disappearance. U S. Redhead (Ur.), Rave off: Politics and deviance in contemporary youth culture (str. 29-40). Aldershot: Avebury.

Muggleton, D. (1997). The post-subculturalist. U S. Redhead, D. Wynne i J. O'Connor (Ur.), The clubcultures reader: Readings in popular cultural studies (str. 167-185). Oxford: Blackwell.

Mungham, G. (1976). Youth in pursuit of itself. U G. Mungham i G. Pearson (Ur.), Working class youth culture (str. 82-105). London: Routledge \& Kegan Paul.

Nguyen, M. (2001). Tales of an Asiatic geek girl: Slant from paper to pixels. U A. Nelson, T. L. N. Tu i A. H. Hines (Ur.), Technicolor: Race, technology and everyday life (str. 177-190). New York: New York University Press.

Piano, D. (2003). Resisting subjects: DIY feminism and the politics of style in subcultural production. U D. Muggleton i R. Weinzierl (Ur.), The post-subcultures reader (str. 253-265). Oxford: Berg Press.

Pini, M. (1997a). Cyborgs, nomads and raving feminine. U H. Thomas (Ur.), Dance in the city (str. 111-129). New York: Macmillan.

Pini, M. (1997b). Woman and the early British Rave scene. U A. McRobbie (Ur.), Back to reality: Social experiences and cultural studies (str. 152-169). New York: Manchester University Press.

Polhmeus, T. (1996). Style surfing: What to wear in the 3rd millennium. London: Thames \& Hudson.

Reddington, H. (2003). "Lady" punks in bands: A subculturette? U D. Muggleton i R. Weinzierl (Ur.), The post-subcultures reader (str. 239-252). Oxford: Berg Press.

Wright, M. A. (1998). The Great British ecstasy revolution. U G. McKay (Ur.), DIY Culture: Party and protest in nineties Britain (str. 228-242). London: Verso.

\section{Women and Gender Roles in Post-Subcultural Theory: Example of Rave Culture}

Rašeljka KRNIĆ

Institute of Social Sciences Ivo Pilar, Zagreb

During the seventies and up to the mid-eighties, the Birmingham School subculture theory concept dominated the sociological study of the connectedness of young people, style and musical taste. However, some authors started to question some of the basic postulates of the than understanding of subcultures in the early eighties. Even though the term "post-subcultural" had been used by Chambers as early as 1987, it was introduced into the subcultural discourse by Polhemus (1996) and Muggleton (1997) in the mid-nineties. "Post-subcultural theories" is a 
DRUŠ. ISTRAŽ. ZAGREB GOD. 21 (2012)

BR. $4(118)$

STR. $885-900$

KRNIĆ, R.: ŽENE I... joint name for an entire spectrum of concepts and theories from the early nineties that still study similar phenomena of young people's gatherings, but no longer insist on the conclusions and the terminological apparatus of the subcultural concept. Along with numerous areas of critique relating to the problem of class analysis, the question of resistance, the disregard of local context, the role of media, etc., one of the most significant of them relates to the problem of neglecting the role of women in subcultural spaces, and the one-dimensional understanding of gender roles and the nature of sexuality. Post-subcultural studies bring a far greater number of analyses that focus on the role of women in subcultural practices and cultural production, and pose the questions of female experience and female perspective of subcultural experience. The studies of various electronic music scenes revealed rave culture as a distinctive subcultural space, where traditional gender roles, as well as the meaning of sexuality are redefined through altered communication and interaction practices.

Keywords: Birmingham School, post-subcultural theory, gender roles, rave culture 